\title{
RELEVÂNCIA INFORMACIONAL ATRIBUÍDA AO DISCLOSURE DE GASTOS COM P\&D NO MERCADO DE CAPITAIS BRASILEIRO
}

\author{
VALUE RELEVANCE ASSIGNED TO DISCLOSURE OF R\&D \\ EXPENDITURES IN THE BRAZILIAN CAPITAL MARKET
}

\author{
RELEVANCIA INFORMACIONAL ATRIBUIDA A LA \\ REVELACIÓN DE GASTOS CON I+D EN EL MERCADO DE \\ CAPITALES BRASILEÑO
}

\begin{abstract}
Andrezza de Albuquerque Espíndola
Bacharel em Ciências Contábeis - Universidade

Federal do Ceará, Fortaleza, Brasil

andrezzaespindola@gmail.com

José Glauber Cavalcante dos Santos

Mestre em Administração e Controladoria Universidade Federal do Ceará, Fortaleza, Brasil Doutorando em Administração e Controladoria Universidade Federal do Ceará, Fortaleza, Brasil jglauber_cont@hotmail.com
\end{abstract}

\author{
Alessandra Carvalho de Vasconcelos \\ Doutorado em Engenharia de Produção - \\ Universidade Federal de Santa Catarina, \\ Florianópolis, Brasil \\ Professora Adjunta - Universidade Federal do \\ Ceará, Fortaleza, Brasil \\ alevasconcelos.ufc@gmail.com
}

\author{
Contextus \\ ISSN 1678-2089 \\ ISSNe 2178-9258 \\ Organização: Comitê Científico Interinstitucional \\ Editor Científico: Diego de Queiroz Machado \\ Editor Executivo: Carlos Daniel Andrade \\ Avaliação: double blind review pelo SEER/OJS \\ Recebido em 05/08/2018 \\ Aceito em 01/09/2018 \\ $2^{a}$ versão aceita em 04/09/2018
}

\section{RESUMO}

Buscou-se analisar a relevância de divulgar os gastos com pesquisa e desenvolvimento (P\&D) no mercado de capitais brasileiro no período de 2011 a 2015. O estudo é documental, de natureza quantitativa, reunindo como população 440 empresas de capital aberto listadas na B3. Empregando o modelo de Ohlson (1995), foram coletados dados referentes a lucro líquido, receita líquida, patrimônio líquido, gastos com P\&D (2011-2015) e valor de mercado (2010-2015), resultando em 1.241 observações. Os dados provêm dos relatórios contábeis, notas explicativas e Economatica®. A análise foi realizada através de regressões lineares com dados em painel com efeitos fixos. As hipóteses foram rejeitadas, pois o disclosure dos gastos com P\&D e o valor investido em atividades de $\mathrm{P} \& \mathrm{D}$ não mostraram relevância informacional. Concluiu-se que a divulgação dos gastos com $\mathrm{P} \& \mathrm{D}$ e o valor aplicado nas atividades de P\&D não sinalizam maior probabilidade de obter vantagens competitivas no contexto do mercado de capitais brasileiro.

Palavras-chave: Relevância Informacional; Disclosure; Pesquisa \& Desenvolvimento; Inovação; Intangíveis.

\begin{abstract}
This paper aimed to analyze the value relevance of disclosing research and development (R\&D) expenditures in Brazil's capital market between 2011 and 2015. The study has a documental and quantitative approach and examined a population of 440 public companies listed in B3. Applying Ohlson's model (1995), data were collected concerning earnings, net revenue, equity, R\&D expenditures (2011-2015) and market value (2010-2015), composing a sample of 1,241 observations. These data come from financial statements, explanatory notes and Economatica ${ }^{\circledR}$ database. The analysis used linear regressions with panel data estimation with fixed effects. The hypotheses were rejected because the $R \& D$ expenditure disclosure and the investment in $R \& D$ expenditures are
\end{abstract}


not value relevant. We concluded that $R \& D$ expenditures disclosure and the value applied in $R \& D$ activities do not indicate a greater probability to gain competitive advantage in the context of the Brazilian capital market.

Keywords: Value Relevance; Disclosure; Research \& Development; Innovation; Intangibles.

\section{RESUMEN}

Esta investigación objetivó analizar la relevancia de la divulgación de los gastos con investigación y desarrollo (I+D) en el mercado de capitales brasileño en el período de 2011 a 2015. El estudio es documental, de naturaleza cuantitativa y reúne como población 440 empresas de capital abierto listadas en la B3. En el modelo de Ohlson (1995), se recolectaron datos referentes al resultado neto, los ingresos netos, el patrimonio neto, los gastos de investigación y desarrollo (2011-2015) y el valor de mercado (2010-2015), resultando en 1.241 observaciones. Los datos fueron recolectados de los informes contables, notas explicativas y Economatica®. El análisis fue realizado a través de regresiones lineales con datos en panel con efecto fijo. Las hipótesis fueron rechazadas, pues la divulgación de los gastos de I+D y el valor invertido en actividades de I+D no mostraron relevancia informacional. Se concluyó que la divulgación de los gastos de I \& D y el valor aplicado en las actividades de I+D no señalan mayor probabilidad de obtener ventajas competitivas en el contexto del mercado de capitales.

Palabras clave: Relevancia Informacional; Divulgación; Investigación y Desarrollo; Innovación; Intangibles.

\section{INTRODUÇÃO}

Segundo estabelecido no pronunciamento técnico CPC 00 (R1) - Estrutura Conceitual para Elaboração e Divulgação do Relatório Contábil-Financeiro (CPC, 2011), a informação contábil deve possuir duas características qualitativas fundamentais: relevância e representação fidedigna. A informação contábil será relevante quando for capaz de influenciar as decisões dos usuários, possuir valor confirmatório, preditivo ou ambos, além de ser material. Assumindo essas prerrogativas, a representação fiel do patrimônio da firma e das mudanças econômicas nele ocorridas é uma consequência. O Conceptual Framework for Financial Reporting, base de preparação do CPC 00 (R1), reivindica das entidades um disclosure mais relevante, comparável e transparente nas demonstrações contábeis (IFRS, s.d.).

Como os interesses dos stakeholders são variados, porquanto existe uma ampla e distinta gama de usuários das demonstrações contábeis, isso possibilita analisar a relevância informacional dos agregados contábeis sob diferentes focos (LOPES; SANT'ANNA; COSTA, 2007; ALVES et al., 2011; BEISLAND; HAMBERG, 2013; MADEIRA; COSTA JUNIOR, 2015; SOUZA; BORBA, 2017) e perspectivas do disclosure.

Os estudos sobre value relevance visam avaliar e relacionar a relevância informacional dos números contábeis ao valor de mercado nas empresas (MACHADO; MACEDO; MACHADO, 2015). Assim, a análise de value relevance reúne evidências que sugerem como determinados tipos de disclosure, inclusive as demonstrações contábeis, são informativos, subsidiando as decisões do usuário. Segundo Ohlson (1995), há incentivos para o disclosure, devido à existência de "eventos-informação" relevantes, que poderiam alterar a expectativa de 
Andrezza de Albuquerque Espíndola, José Glauber Cavalcante dos Santos, Alessandra Carvalho de Vasconcelos

lucros futuros em oposição aos correntes e que a contabilidade, ao contrário do mercado, não consegue incorporar. Segundo essa premissa, os resultados contábeis não podem refletir todas as informações disponíveis no mercado.

Ohlson (1995) desenvolveu uma "teoria da relevância informacional", que propõe um modelo em que o valor atribuído à empresa pelo mercado é função de três componentes: o patrimônio residual, os lucros anormais e outras informações relevantes. O último componente é indiscriminado no modelo, sugerindo que o mercado antecipa ganhos ou perdas originadas de agregados informacionais que a contabilidade ainda não incorporou ao disclosure, mas poderá vir a fazê-lo no futuro. Nesse sentido, Beaver (1968) destaca que a informação dita relevante altera as expectativas dos investidores, sendo essa mudança grande o suficiente para modificar a decisão de investimento. Essa é a definição que contribui para obter consenso sobre o valor informativo do lucro e seu determinismo sobre o preço atribuído à firma. A posição de Beaver (1968) é reforçada por Lo (2010), segundo o qual é através da mudança potencial de expectativas que se determina a relevância informacional de um item. Portanto, não é por ser economicamente representativo que um agregado informacional será relevante. Caso ele sofra antecipação pelo mercado, não se configura a mudança de expectativas, mas apenas a sua confirmação, descaracterizando-se a relevância informacional.

Diversos estudos têm argumentado em favor da essencialidade de determinadas posturas corporativas ou estratégias, destacando-se proeminentemente o perfil inovador. Nesse sentido, os gastos com inovação, representados pelos dispêndios da firma para obter novos produtos, processos ou serviços, podem também ocasionar vantagens competitivas, podendo levar a empresa ao alcance de uma melhor performance (BARNEY, 1991; BAAIJ; GREEVEN; VAN DALEN, 2004; CARVALHO; KAYO; MARTIN, 2010; ZEMPLINEROVÁ; HROMÁDKOVÁ, 2012; SANTOS et al., 2014).

Diante disso, a inovação de produtos e serviços ofertados ao mercado e a geração de conhecimento atribuída às atividades de pesquisa e desenvolvimento $(\mathrm{P} \& \mathrm{D})$ são variáveis que contribuem para gerar retornos para os investidores, além da expectativa de aumentar a competitividade, fatos esses capazes de explicar a motivação para os gastos com P\&D (RODRIGUES; ELIAS; CAMPOS, 2015). Como afirmam Jensen, Menezes-Filho e Sbragia (2004), o dispêndio com P\&D é um dos fatores que mais influenciam, de maneira ativa, o processo de inovação. Por tal razão, os investidores poderiam interpretar as informações sobre o potencial inovador da empresa como maiores chances de obter vantagens competitivas 
sustentáveis frente à concorrência. Por outro lado, de acordo com March (1991), as atividades de inovação baseadas em P\&D são mais arriscadas e produzem retornos mais voláteis e incertos. Para esse caso, os investidores podem interpretar a divulgação de gastos com P\&D como sinal de risco e elevação de custos (SILVA; BRAGA; REBOUÇAS, 2017).

Contudo, os estudos envolvendo a temática apontaram inconsistências em tal correlação entre o impacto de divulgar os gastos com P\&D e os valores de mercado nas firmas (ALVES et al. 2011). Alves et al. (2011) observaram que a divulgação desses gastos não adiciona ganhos informacionais ao lucro. Similarmente, Brito, Brito e Morganti (2009) asseguram que a incerteza sobre os efeitos da inovação estende-se ao desempenho empresarial, ou seja, o dispêndio com P\&D não é capaz de influenciar a lucratividade da empresa. Em sentido oposto, Lee e Shim (1995) investigaram o impacto na performance de longo prazo em empresas americanas e japonesas de alta tecnologia, constatando uma correlação positiva entre P\&D e crescimento no mercado japonês. Azevedo e Gutierrez (2009), por seu turno, analisando apenas as firmas listadas na Bolsa de Valores de Nova York (Nyse), também verificaram que os gastos com $\mathrm{P} \& \mathrm{D}$ conduziam favoravelmente ao crescimento da firma.

De maneira mais pontual, Nguyen, Nivoix e Noma (2010) avaliaram se as empresas que realizam altos gastos com $P \& D$ vinham subestimando seu valor de mercado, dada a dificuldade de mensurar a geração de retorno futura e no longo prazo de tais investimentos, argumento alinhado com March (1991). A hipótese levantada na pesquisa, de que a causa da desvalorização dos investimentos estava correlacionada com os gastos com $\mathrm{P} \& \mathrm{D}$, foi rejeitada, porque Nguyen, Nivoix e Noma (2010) não observaram nenhuma evidência de subestimação de valores no mercado de ações, nesse caso o japonês.

Diante do exposto, percebe-se que a inovação via realização de gastos com P\&D é capaz de acrescentar conteúdo informacional relevante ao investidor durante o processo de atribuir valor à firma. Destarte, a gestão pode sinalizar, para o mercado, benefícios ou custos econômicos com o disclosure dos gastos com P\&D (MARCH, 1991). A divulgação é uma forma utilizada pela empresa para se diferenciar das demais, subsidiando o processo decisório e facilitando compatibilidades com as expectativas e preferências do investidor (AKERLOF, 1970; SIMON, 1955; SPENCE, 1973). Portanto, em meio à problemática da relevância informacional captada pelo mercado de capitais brasileiro no que tange aos gastos com $\mathrm{P} \& \mathrm{D}$, esta pesquisa procura responder o seguinte questionamento: qual o value relevance do disclosure de gastos com P\&D e do valor gasto com a atividade nas firmas no mercado de 
capitais brasileiro?

Objetiva-se analisar a relevância da divulgação dos gastos com P\&D para o mercado de capitais brasileiro no período de 2011 a 2015. Consideram-se as recomendações da literatura e a afirmação de Souza e Borba (2017, p. 79) de que, de modo geral, os estudos sobre value relevance "divergem, dependendo do país de realização da pesquisa". Com isso, pretende-se investigar os efeitos dos dispêndios com $\mathrm{P} \& \mathrm{D}$ na expectativa do investidor e contribuir para o entendimento da relevância informacional captada pelo mercado acionário brasileiro quanto a esses investimentos, importantes para desenvolver capacidades e gerar novos conhecimentos, instrumentos e metodologias a serem incorporados em novos produtos e processos, capazes de proporcionar melhor desempenho organizacional (CARAYANNIS; SAMARA; BAKOUROS, 2015; CARMONA; TOMELIN; HEIN, 2018).

\section{REFERENCIAL TEÓRICO}

A contabilidade incorpora componentes informacionais heterogêneos no disclosure, e isso explica a diversidade de estudos debruçados sobre o problema da identificação dos itens capazes de explicar o valor das firmas. Devido à postura conservadora assumida pela contabilidade, o lucro não é capaz de incorporar todas as informações disponíveis para o mercado. Tais agregados informacionais podem modificar o comportamento e as expectativas dos investidores, pois, apesar de não constituírem o lucro corrente, afetam o lucro de períodos seguintes. Assim, quando dotadas de value relevance, as informações impactam os resultados e explicam o valor das firmas, com certa defasagem temporal e com impacto gradual no longo prazo (BEAVER, 1968; OHLSON, 1995).

A correlação entre relevância e capacidade da informação contábil de afetar as decisões dos stakeholders ocorre quando a contabilidade, ao fornecer uma informação nova, é capaz de alterar a expectativa de desempenho futuro da firma de tal forma que o investidor revisa suas expectativas quanto à compra e venda das ações e consequente precificação da firma (FRANCIS; SCHIPPER, 1999). Romney e Steinbart (2000, p. 15) destacam a relevância da informação contábil para os mercados, pois ela "reduz a incerteza, melhora a habilidade de fazer previsões e permite corrigir ou confirmar expectativas". Considerando-se o exposto, a percepção de utilidade do agregado contábil se dá apenas quando as informações são relevantes para as necessidades dos usuários ao tomar decisões, influenciando as suas opções econômicas 
(BEAVER, 1968). Em outras palavras, determinado item contábil pode ser relevante e material para certo grupo de stakeholders e não o ser para outro (LO, 2010), isso porque a utilidade e o interesse do usuário é que definem o value relevance atribuído.

Diante disso, Ohlson (1995) estabeleceu que o valor atribuído à empresa é uma função de agregados contábeis tradicionais (lucro residual e patrimônio líquido) e outros eventos que afetam lucros futuros, e, percebidos pelo mercado, modificam suas expectativas.

Holthausen e Watts (2001) estabeleceram três categorias de estudo acerca do value relevance: (i) estudos de associação relativa - investigam a associação entre os preços de mercado e os números contábeis sujeitos aos diferentes normativos contábeis. Nesse grupo, a norma que produzir o número contábil mais relevante será aquela com a maior regressão de $\mathrm{R}^{2}$; (ii) estudos de associação incremental - analisam se a explicação do número contábil é útil para demonstrar o valor (ou retorno) de títulos em períodos mais longos, considerando também outras variáveis. O número contábil é relevante se o coeficiente da regressão for positivo; (iii) estudos de conteúdo informacional marginal - avaliam a agregação de conteúdo informacional do número contábil à divulgação. Para tanto, os estudos de eventos são utilizados para se verificar a correlação entre a divulgação de um número contábil e as variações dos valores na cotação dos títulos. A maioria dos estudos pertence aos dois primeiros grupos, incluindo esta pesquisa.

Observado o problema da assimetria informacional determinada pelas diferenças entre gestores e stakeholders (DYE, 1985; MYERS; MAJLUF, 1984), principalmente no que tange às informações que impactam o processo decisório (BALL; BROWN, 1968; BEAVER, 1968; BROWN; LO; LYS, 1999), a literatura pressupõe que o disclosure beneficia a correlação entre os retornos atuais e os resultados futuros (LUNDHOLM; MYERS, 2002). Segundo Miller (2002), o mercado responde positivamente ao disclosure, porque ocorre uma redução da assimetria informacional e um aumento da eficiência na alocação dos recursos e investimentos (AKERLOF, 1970).

Nesse ponto, se o disclosure pode vir a alterar as expectativas e o comportamento dos stakeholders (BEAVER, 1968; OHLSON, 1995), assume-se que o relato sobre os gastos com P\&D pode funcionar como um sinal para o mercado (SIMON, 1955; SPENCE, 1973). Esse sinal pode ser interpretado positiva ou negativamente em função das expectativas sobre retornos futuros e riscos (MARCH, 1991). Segundo Cruz (2007), a busca por vantagens competitivas deve ser permanente, e isso cada dia mais se integra ao uso de ativos intangíveis vinculados à 
Andrezza de Albuquerque Espíndola, José Glauber Cavalcante dos Santos, Alessandra Carvalho de Vasconcelos

inovação. Brito, Brito e Morganti (2009), porém, atentam para a dificuldade de mensuração da inovação, bem como para a identificação de sua correlação com o desempenho nas empresas. Segundo os autores, a inovação é um possível diferencial na lucratividade e também no crescimento da firma. Apesar disso, Cho e Pucik (2005) inferiram haver correlação direta entre inovação e crescimento, mas indireta entre inovação e lucratividade, em as empresas americanas com alta reputação.

De acordo com Chaney, Timothy e Russell (1991), diversas análises empíricas têm demonstrado uma correlação consistente entre os indicadores concernentes à inovação, como os gastos com P\&D, e o desempenho empresarial. Nesse sentido, Santos, Vasconcelos e De Luca (2013) estabelecem que a inovação se destaca como forte aliada da organização no que tange à geração de vantagens competitivas. É possível, portanto, observar que os dispêndios com P\&D têm se tornado mais frequentes, e, por isso, devido ao alto grau de competitividade no mercado de capitais, a capacidade de inovação tecnológica, com foco em gastos em P\&D, demonstra ter maior importância (ANDREASSI; SBRAGIA, 2002).

A divergência observada entre os resultados de estudos sobre os reflexos da inovação, seja no desempenho, no valor ou na construção de vantagens competitivas, conduziu diversas pesquisas em busca de evidências que demonstrassem como a atividade de inovação é captada pelo mercado. Essa discussão torna-se mais pertinente em mercados emergentes como o Brasil, demarcado pela concentração acionária em virtude do ambiente de fraca proteção legal para acionistas e credores. Esse cenário pode favorecer a expropriação de acionistas minoritários, e a divulgação ajuda a evitar esse tipo de conflito de interesses (TERRA; LIMA, 2006).

Segundo Minetti, Murro e Paiella (2015), a concentração acionária influencia negativamente a atividade de inovação, com maior impacto nos gastos com P\&D. Acionistas majoritários e firmas familiares poderiam ser avessos ao risco associado à atividade de inovação por meio de gastos com P\&D. Conforme Teh, Kayo e Kimura (2008), a contribuição da inovação para o valor da empresa também é incerta. Em seu estudo, as marcas e patentes, indicadores de inovação resultantes das atividades de P\&D, não tinham correlação com o valor nas empresas brasileiras. Os autores concluem que isso pode ser uma questão estrutural, porque o Brasil investe pouco em atividades de P\&D. Diante desse quadro, a relevância informacional dos gastos com P\&D foi investigada em vários contextos, como sintetiza a Quadro 1. 
Quadro 1 - Estudos empíricos relacionados

\begin{tabular}{|c|c|}
\hline Autoria & Objetivo, contexto investigado e principais resultados \\
\hline Oswald (2008) & $\begin{array}{l}\text { Investiga os determinantes e a relevância informacional da escolha do método contábil } \\
\text { para o desenvolvimento de gastos com P\&D em firmas do Reino Unido. Foram analisadas } \\
3.229 \text { empresas no período de } 1990 \text { a } 2004 \text {. Há uma pequena diferença de relevância } \\
\text { informacional entre P\&D capitalizado e P\&D reconhecido como despesa. A escolha } \\
\text { contábil é influenciada pela variabilidade e sinalização dos lucros. A adequada divulgação } \\
\text { dos gastos com P\&D melhora a comunicação da informação. }\end{array}$ \\
\hline $\begin{array}{l}\text { Franzen e } \\
\text { Radhakrishnan } \\
\quad(2009)\end{array}$ & $\begin{array}{l}\text { Examina se a relevância da informação de P\&D para as empresas deficitárias estende-se } \\
\text { às superavitárias. Foram analisadas } 47.167 \text { companhias que realizaram gastos com P\&D } \\
\text { entre } 1982 \text { e 2002, listadas na Compustat, sendo } 18.636 \text { deficitárias e } 28.531 \\
\text { superavitárias. Os resultados mostram que os lucros das empresas superavitárias contêm } \\
\text { informações sobre os benefícios futuros das atividades de P\&D, enquanto nas empresas } \\
\text { deficitárias não ocorre o mesmo. }\end{array}$ \\
\hline $\begin{array}{l}\text { Alves et al. } \\
\quad(2011)\end{array}$ & $\begin{array}{l}\text { Analisa a relevância dos gastos com P\&D para o mercado de capitais no setor de } \\
\text { distribuição de energia elétrica no período de } 2002 \text { a } 2009 \text {. A informação dos gastos com } \\
\text { P\&D não acrescenta conteúdo informacional marginal no que tange à tentativa de } \\
\text { explicação do valor de mercado das empresas investigadas. }\end{array}$ \\
\hline $\begin{array}{l}\text { Atoche, López e } \\
\text { Ruiz (2012) }\end{array}$ & $\begin{array}{l}\text { Contrasta a relevância do valor das despesas atuais de P\&D com defasagem de um ano } \\
\text { econômico. A amostra reúne } 96 \text { companhias abertas do setor automotivo americano } \\
\text { listadas no período de } 1995 \text { a } 2004 \text {. Notou-se que os investidores consideram os gastos } \\
\text { com P\&D atuais e de exercícios anteriores não relevantes para definir o valor de mercado. }\end{array}$ \\
\hline $\begin{array}{c}\text { Jiang e Stark } \\
\quad(2013)\end{array}$ & $\begin{array}{l}\text { Investiga pesquisas prévias sobre relevância informacional contábil para firmas } \\
\text { deficitárias, ao possibilitar que o coeficiente de valor contábil varie em três conjuntos } \\
\text { distintos de observações de firmas. Compuseram a análise } 3.931 \text { companhias deficitárias } \\
\text { no período de } 1991 \text { a } 2010 \text {. Os resultados apontam que o valor contábil é o determinante } \\
\text { menos importante do valor patrimonial das empresas que investem alto em P\&D. }\end{array}$ \\
\hline $\begin{array}{l}\text { Rodrigues, Elias e } \\
\text { Campos (2015) }\end{array}$ & $\begin{array}{l}\text { Verifica o value relevance da informação sobre gastos com P\&D em empresas brasileiras, } \\
\text { analisando se a padronização internacional elevou a relevância dessa informação no } \\
\text { mercado. Compuseram a análise de relevância } 326 \text { empresas que detinham dados anuais } \\
\text { para o período de } 2003 \text { a } 2012 \text {. Os resultados encontrados sinalizam que, após a } \\
\text { implementação dos padrões informacionais, a informação de P\&D passou a ser relevante } \\
\text { para o mercado brasileiro. }\end{array}$ \\
\hline $\begin{array}{c}\text { Gong e Wang } \\
(2016)\end{array}$ & $\begin{array}{l}\text { Analisa se a natureza das diferenças entre os princípios contábeis aceitos nacionalmente e } \\
\text { as IFRS associam-se ao diferencial de mudanças da relevância informacional dos gastos } \\
\text { com P\&D após a adoção das IFRS em nove países entre } 1997 \text { e 2012. A adoção das IFRS } \\
\text { mostrou uma diminuição da relevância dos gastos com P\&D em países que anteriormente } \\
\text { exigiam gastos imediatos ou capitalização opcional. Os achados do estudo apontam ainda } \\
\text { que, em países com maior proteção ao investidor, as mudanças na relevância foram } \\
\text { maiores. }\end{array}$ \\
\hline $\begin{array}{l}\text { Songur e Heavilin } \\
\qquad(2017)\end{array}$ & $\begin{array}{l}\text { Investiga a correlação entre investimentos anormais em P\&D e os retornos esperados. } \\
\text { Foram analisadas } 4.561 \text { empresas listadas na Nyse, na American Stock Exchange (Amex) } \\
\text { e na Nasdaq no período de } 1975 \text { a } 2015 \text {. Concluiu-se que, ao aumentarem anormalmente } \\
\text { seus investimentos em P\&D, as companhias auferem rendimentos mais altos em } \\
\text { comparação com o portfólio de mercado. }\end{array}$ \\
\hline
\end{tabular}

Fonte: elaboração própria.

Observa-se que os estudos, predominantemente estrangeiros, não são consensuais quanto aos efeitos da inovação, com foco em $\mathrm{P} \& \mathrm{D}$, no valor da firma e em relação à informatividade dos gastos com P\&D. Essa incongruência reforça a necessidade de estudos que explorem a lacuna (BRITO; BRITO; MORGANTI, 2009). Adicionalmente, deve-se ressaltar que o aparente conflito de resultados pode demonstrar que o engajamento das empresas com atividades de inovação seja explicado pelos sistemas nacionais de inovação. Isso significa que 
a estrutura, o desenvolvimento da indústria e a competitividade do mercado podem explicar o interesse pela inovação (TEH; KAYO; KIMURA, 2008). Seria natural, por exemplo, que em mercados em que a inovação não é incentivada, os investidores não interpretem essa informação como relevante, ou até percebam apenas os riscos econômicos e os custos associados a atividades de $\mathrm{P} \& \mathrm{D}$. A maioria dos estudos citados sobre o value relevance de gastos com $\mathrm{P} \& \mathrm{D}$ tem aplicação em empresas de países desenvolvidos, e muitos deles investigam a interferência da padronização contábil no value relevance.

Diante disso, acredita-se que esta pesquisa contribui para enriquecer a literatura contábil sobre a relevância informacional atribuída a itens contábeis e não contábeis, principalmente aqueles referentes ao perfil inovador das firmas. Esses estudos aparentemente são menos frequentes em mercados emergentes, como o Brasil. O período de análise é também um diferencial do estudo, isso porque considera cinco exercícios contábeis imediatamente seguintes à obrigatoriedade de adequação à padronização via IFRS, quando se consolidou a convergência em caráter integral. O estudo é abrangente, e considera todas as empresas listadas na B3 Brasil, Bolsa, Balcão à época da coleta, constituindo uma pesquisa intersetorial, diferentemente da obra de Alves et al. (2011), e similar à de Rodrigues, Elias e Campos (2015).

Nesse sentido, a pesquisa considera que a inconsistência do relacionamento entre a inovação, o valor de mercado e o desempenho pode ser esclarecida por meio da análise de value relevance dos gastos com $\mathrm{P} \& \mathrm{D}$, já que o alinhamento entre desempenho e relevância pode não ser concomitante. Isso é justificado pela defasagem temporal e a incapacidade da contabilidade de incorporar todas as informações disponibilizadas para o mercado (BALL; BROWN, 1968; BEAVER, 1968; OHLSON, 1995). Com base na breve discussão acadêmica apresentada e na problemática identificada, o estudo formula as seguintes hipóteses:

H1: a divulgação dos gastos com P\&D tem relevância informacional no mercado de capitais brasileiro.

H2: o montante gasto com P\&D tem relevância informacional no mercado de capitais brasileiro.

Distintamente dos estudos anteriores, consideram-se nesta pesquisa dois sinais emitidos pelas empresas no mercado de capitais brasileiro. O primeiro é a busca pela inovação $\left(\mathbf{H}_{1}\right)$, e a firma sinaliza seu comprometimento estratégico. O segundo sinal é o esforço inovador $\left(\mathbf{H}_{2}\right)$, demonstrando quão comprometida com a inovação é a empresa. Espera-se, neste estudo, que os gastos com P\&D sinalizem a perspectiva de obtenção de vantagens competitivas futuras para 
os investidores, incrementando assim o valor das firmas, como sugere uma parcela da literatura mencionada (AZEVEDO; GUTIERREZ, 2009; GU; LI, 2003; LEE; SHIM, 1995), por meio do impacto positivo no crescimento ou no desempenho das empresas. Essa perspectiva é contrária aos resultados obtidos por Alves et al. (2001), Santos et al. (2014) e Teh, Kayo e Kimura (2008), investigando o mercado brasileiro.

A pesquisa justifica-se na medida em que corrobora a literatura sobre value relevance, ao identificar as informações potencialmente capazes de modificar a expectativa e as decisões econômicas dos investidores. Destaca-se aqui que o estudo aprofunda as discussões em torno da importância que é dedicada pelas empresas, no mercado acionário brasileiro, às estratégias de comprometimento com a inovação, que têm ganhado relevância no contexto corporativo. A investigação reproduz resultados que ajudam a entender o comportamento do mercado diante do disclosure de informações que poderiam sinalizar maiores riscos ao negócio ou a promessa de vantagens competitivas sustentáveis. Outro aspecto a considerar é a reunião de evidências sobre a informatividade de um agregado contábil de divulgação obrigatória, na vigência do pronunciamento técnico CPC 04 (R1), iniciada em 2010.

\section{METODOLOGIA}

\subsection{Caracterização do estudo, população e amostra}

O estudo é considerado descritivo, já que registra e descreve as evidências relativas à problemática da relevância informacional dos gastos com P\&D. Trata-se, ainda, de pesquisa documental, utilizando dados exclusivamente secundários publicados pelas empresas nas suas demonstrações financeiras. O estudo assume abordagem quantitativa para o objetivo proposto, no que tange ao tratamento e análise dos resultados.

Procurando reunir evidências do value relevance no mercado acionário brasileiro atribuído aos gastos com P\&D, o estudo adotou como população as 440 firmas de capital aberto listadas na B3 em 3 de janeiro de 2017, segundo o website da instituição. Considerou-se um horizonte temporal amplo de análise (2011-2015), incluindo os cinco anos mais recentes na data de início do processo de seleção e coleta de dados. A disponibilidade dos dados foi o critério de inclusão das firmas na pesquisa, na forma a seguir: valor de mercado (2010-2015) e patrimônio líquido, lucro líquido e receita líquida (2011-2015). Realizados todos os 
Andrezza de Albuquerque Espíndola, José Glauber Cavalcante dos Santos, Alessandra Carvalho de Vasconcelos

procedimentos de coleta, alcançou-se uma amostragem anual variada, totalizando 1.241 observações, assim distribuídas: 2011 - 227 empresas, 2012 - 251 empresas, 2013 - 253 empresas, 2014 - 259 empresas e 2015 - 251 empresas.

\subsection{Modelo econométrico e análise}

Para a análise de relevância proposta, utilizou-se uma adaptação do modelo de Ohlson (1995). Esse ajuste foi empregado por Aharony, Barniv e Falk (2010), Atoche, López e Ruiz (2012), Hamberg e Beisland (2014), Machado, Macedo e Machado (2015), Potin, Bortolon e Sarlo Neto (2016) e Siekkinen (2016), simplificando-se o modelo autorregressivo, mediante utilização do lucro corrente em vez do lucro residual. Essa estrutura pode evitar distorções de escala do lucro residual entre as firmas - desde que ajustadas as variáveis -, além de reduzir a perda de observações. O modelo é representado pela Equação 1:

$$
V m_{i, t}=\beta_{0}+\beta_{1} P l_{i, t}+\beta_{2} L L_{i, t}+\beta_{3} O I_{i, t}+\varepsilon_{i, t}(1)
$$

Em que:

$V m_{i, t}$ é o valor de mercado da empresa $i$ no ano $t$, deflacionado por $V m_{i, t-1}$;

$P l_{i, t}$ é o valor do patrimônio líquido da empresa $i$ no ano $t$, deflacionado por $V m_{i, t-1}$;

$L L_{i, t}$ é o lucro líquido da empresa $i$ no ano $t$, deflacionado por $V m_{i, t-1}$;

$O I_{i, t}$ são as outras informações previstas no modelo de Ohlson (1995), que compreende a divulgação de gastos com $\mathrm{P} \& \mathrm{D}$ e o valor gasto com $\mathrm{P} \& \mathrm{D}$ sobre a receita líquida $\operatorname{Rec}_{i, t}$

$\beta_{0}$ é o intercepto;

$\beta_{1}, \beta_{2}$, e $\beta_{3}$ são os coeficientes angulares; e

$\varepsilon_{i, t}$ é o termo de erro.

$V m_{i, t}$ foi obtido no banco de dados Economática®;

$P l_{i, t}, L L_{i, t}$ e $\operatorname{Rec}_{i, t}$ foram extraídos do Balanço Patrimonial e da Demonstração do Resultado do Exercício de cada companhia.

O montante dos gastos com P\&D foi coletado nas Notas Explicativas de cada empresa. A Equação 1 foi estimada com regressões de dados em painel com efeitos fixos, considerandose, dessa forma, as individualidades de cada observação e a heterogeneidade da amostra no que tange ao esforço inovador. 
A análise de relevância proposta verifica se a divulgação de gastos com P\&D (H1) e o valor gasto com P\&D ( $\left.\mathbf{H}_{2}\right)$ seriam fatores informativos de distinção do valor da firma no mercado de capitais brasileiro. Na hipótese $\mathbf{H}_{1}, O I_{i, t}$ é uma variável dicotômica; já na hipótese $\mathbf{H}_{2}, O I_{i, t}$ corresponde a $P e D_{i, t} / \operatorname{Rec}_{i, t}$, sendo $P e D_{i, t}$ o montante gasto com P\&D e $\operatorname{Rec}_{i, t}$ a receita líquida, ambos da firma $i$ no ano $t$. Essa escala é considerada adequada ao objetivo do estudo, já que a intenção é verificar como o impacto financeiro do financiamento de atividades de inovação é precificado pelo mercado. Lee e Shim (1995) também deflacionam o accrual referente ao reconhecimento dos gastos com $P \& D$ pela receita líquida. As pesquisas de Ahmed e Falk (2006), Atoche, López e Ruiz (2012), Franzen e Radhakrishnan (2009), Gong e Wang (2016), Oswald (2008) e Songur e Heavilin (2017) também recorrem ao escalonamento do gasto com P\&D para evitar distorções de escala no modelo autorregressivo. Esse ajuste é importante na aplicação dos modelos de value relevance (BROWN; LO; LYS, 1999).

Considerando todos esses aspectos, foram determinados dois critérios de análise (um amplo e um restrito) com base na Equação 1. A matriz critério x painel x especificação da variável resultou em dez diferentes estimações, como mostra a Tabela 1.

Tabela 1 - Sumário de análise quantitativa - Equação 1

\begin{tabular}{cllrl}
\hline Modelo & Critério & \multicolumn{1}{c}{ Painel } & Observações & \multicolumn{1}{c}{ Especificação dos modelos } \\
\hline 1 & Amplo & Desbalanceado & 1.241 & Modelo original de Ohlson (1995) sem $O I_{i, t}$ \\
2 & Amplo & Desbalanceado & 1.241 & $O I_{i, t}$ é dummy \\
3 & Amplo & Desbalanceado & 1.241 & $O I_{i, t}$ é contínua, representada por $P e D_{i, t} / \operatorname{Rec}_{i, t}$ \\
4 & Amplo & Balanceado & 1.005 & Modelo original de Ohlson (1995) sem $O I_{i, t}$ \\
5 & Amplo & Balanceado & 1.005 & $O I_{i, t}$ é dummy \\
6 & Amplo & Balanceado & 1.005 & $O I_{i, t}$ é contínua, representada por $P e D_{i, t} / \operatorname{Rec}_{i, t}$ \\
7 & Restrito & Desbalanceado & 208 & Modelo original de Ohlson (1995) sem $O I_{i, t}$ \\
8 & Restrito & Desbalanceado & 208 & $O I_{i, t}$ é contínua, representada por $P e D_{i, t} / \operatorname{Rec}_{i, t}$ \\
9 & Restrito & Balanceado & 145 & Modelo original de Ohlson (1995) ${\operatorname{sem~} O I_{i, t}}_{1, t} \operatorname{Rec}_{i, t}$ \\
\hline
\end{tabular}
Fonte: elaboração própria.

O critério amplo se baseia no fato de que, para a IAS 38 - Intangible Assets (IAS PLUS, s.d), que trata da mensuração, reconhecimento e divulgação de ativos intangíveis pelas empresas, em que se baseia o pronunciamento técnico CPC 04 (CPC, 2010), as firmas devem divulgar o total gasto com $\mathrm{P} \& \mathrm{D}$ reconhecido como despesa do período, ou seja, dispêndios que não atendem aos critérios para capitalização do gasto e sugerem haver incerteza na mensuração e controle de benefícios econômicos. À luz dessa prerrogativa normativa, procedeu-se da seguinte forma: a não ocorrência de relato gerou atribuição de zero para a variável $O I_{i, t}$, na divulgação $\left(\mathbf{H}_{1}\right)$ e também no gasto da empresa $\left(\mathbf{H}_{2}\right)$. Logo, $O I_{i, t}$ é variável dicotômica 
Andrezza de Albuquerque Espíndola, José Glauber Cavalcante dos Santos, Alessandra Carvalho de Vasconcelos

(divulgação) e contínua (parcela do gasto com P\&D da receita líquida), dependendo da análise suscitada. Para o critério restrito, são consideradas apenas as firmas que tinham gastos com $\mathrm{P} \& \mathrm{D}$ evidenciados nas Notas Explicativas, sendo $O I_{i, t}$ somente a variável contínua.

Para o teste das hipóteses e verificação da relevância informacional da variável de interesse, tomou-se a significância estatística do coeficiente $\beta_{3}$, sendo $\beta_{3}>0$ e significante, caso em que se assume que há ganho informacional e o mercado percebe os gastos com P\&D sinalizando benefícios econômicos futuros, aumentando o valor atribuído à firma. Sendo $\beta_{3}<$ 0 e significante, também há o ganho informacional, porém desta vez o mercado percebe os gastos com P\&D como um indício de custos econômicos futuros, pois as atividades de inovação não são efetivas, e tendem a não gerar retornos incrementais, levando à redução do valor atribuído à firma (ATOCHE; LÓPEZ; RUIZ, 2012; MARCH, 1991). Se $\beta_{3}$ não possui significância estatística, o mercado assume uma postura de indiferença em relação aos gastos com P\&D, não interessando para o mercado a adoção de uma postura estratégica inovadora.

\section{ANÁLISE E DISCUSSÃO DOS RESULTADOS}

\subsection{Caracterização dos gastos com P\&D}

A análise de value relevance dos gastos com P\&D propriamente dita é antecedida pela caracterização da variável de interesse no contexto investigado. Assim, destaca-se, como primeira inferência, que nas firmas integrantes do mercado acionário brasileiro é tímido o comprometimento com a inovação por meio de atividades de P\&D no período. Das 440 firmas inicialmente consideradas, apenas 65 (14,8\%) em 2011,70 (15,9\%) em 2012,64 (14,5\%) em 2013,64 (14,5\%) em 2014 e 66 (15\%) em 2015 reconheceram e, portanto, divulgaram gastos com P\&D nas suas Notas Explicativas. Esse cenário ratificaria a frágil estrutura das firmas no que tange à inovação no Brasil, segundo Teh, Kayo e Kimura (2008).

Conjectura-se que o ambiente econômico de baixa proteção a investidores e credores, somado à elevada concentração acionária, pode funcionar como um mecanismo de desestímulo à inovação. Nesse sentido, a governança corporativa pode ser um aspecto positivo, já que os recursos intangíveis são mais suscetíveis a ações de agentes que levem à expropriação. Destarte, com a governança, as firmas sinalizariam maior proteção contra conflitos de agência, servindo 
de incentivo para atividades de inovação (MINETTI; MURRO; PAIELLA, 2015; TERRA; LIMA, 2006).

Analisando o contexto das empresas listadas na Nyse no período de 2001 a 2007, Azevedo e Gutierrez (2009) inferiram que apenas 8,6\% das firmas realizaram e divulgaram gastos com P\&D. Santos et al. (2016) identificaram 76 dentre 524 listadas na B3 no período 2011-2012, correspondente a aproximadamente 15\% do seu grupo de análise, resultado semelhante àquele apresentado por este estudo.

O perfil apresentado não foi integralmente contemplado pela análise de value relevance prevista, devido a restrições de disponibilidade de dados das empresas nas bases de dados. Logo, o grupo de análise foi substancialmente reduzido. Deve-se destacar essa como uma importante limitação que restringe as inferências obtidas na presente pesquisa com a aplicação do modelo de Ohlson (1995). A amostra de firmas com P\&D passou a ter a seguinte distribuição anual: 2011 - 41 (18,1\%), 2012 - 45 (17,9\%), 2013 - 38 (15\%), 2014 - 42 (16,2\%) e 2015 $42(16,7 \%)$.

Apesar da redução do total de observações, a participação relativa de empresas com P\&D em cada amostra anual teve aumento de até $3 \%$ em decorrência das exclusões. Definitivamente restrita a amostragem, apresenta-se na Tabela 2 o comportamento dos gastos com $\mathrm{P} \& \mathrm{D}$, nessas empresas, em relação à receita líquida (razão $P e D_{i, t} / \operatorname{Rec}_{i, t}$ ), apenas nas firmas que divulgaram o accrual P\&D em Notas Explicativas.

Tabela 2 - Proporção dos gastos com P\&D em relação à receita líquida em firmas divulgadoras (\%) - 2011-2015

\begin{tabular}{lrrrrr}
\hline \multicolumn{1}{c}{ Estatística descritiva } & $\mathbf{2 0 1 1}$ & $\mathbf{2 0 1 2}$ & $\mathbf{2 0 1 3}$ & $\mathbf{2 0 1 4}$ & \multicolumn{1}{c}{$\mathbf{2 0 1 5}$} \\
\hline Mínimo & 0,001 & 0,0008 & 0,0002 & 0,0008 & 0,0006 \\
Média & 1,0051 & 0,9292 & 0,8337 & 1,2757 & 1,2806 \\
Mediana & 0,4459 & 0,6387 & 0,6137 & 0,7986 & 0,5575 \\
Máximo & 9,1201 & 4,9937 & 2,8567 & 11,9318 & 12,8718 \\
Coeficiente de variação & 160 & 123 & 101 & 156 & 172 \\
\hline
\end{tabular}

Fonte: elaboração própria.

Os dados da Tabela 2 mostram que não só a participação das empresas em atividades de inovação por meio de $\mathrm{P} \& \mathrm{D}$ é inexpressiva. No mercado brasileiro, também é pequeno o investimento nessas atividades. Em resumo, poucas empresas optam por financiar projetos que podem gerar vantagens competitivas de diferenciação, e, mesmo aquelas que assumem os riscos desses projetos, escolhem sacrificar uma parcela pouco representativa de recursos, salvo poucas exceções. O gasto médio com P\&D oscilou entre $0,8 \%$ e $1,3 \%$ da receita líquida no período de análise. Metade das empresas gastou com P\&D entre 0,4\% e 0,8\% das suas receitas nos cinco anos. Enquanto algumas poucas empresas investem maciçamente em inovação, visto isso por 
Andrezza de Albuquerque Espíndola, José Glauber Cavalcante dos Santos, Alessandra Carvalho de Vasconcelos

meio do percentual máximo, que chegou a 12,9\% em 2015, outras apresentaram gastos imateriais, por exemplo, de 0,001\% em 2011. A heterogeneidade do grupo em relação aos gastos com P\&D é sinalizada pela alta dispersão dos valores em torno da média.

Segundo Oliveira et al. (2015), o Brasil gastou, em média, 1\% do Produto Interno Bruto (PIB) com P\&D (2000-2011), o que está alinhado com os resultados apresentados. O perfil dos setores econômicos da amostra evidencia sete grandes grupos integrados por 53 diferentes firmas. A indústria e o setor de energia elétrica respondem por $42 \%$ das empresas, cada. A indústria se destaca em razão da natureza econômica da atividade, pois a necessidade de produção leva a investir mais em P\&D como uma forma de obter diferencial no mercado e, também, vantagem competitiva (CRUZ, 2007) - foram identificadas 13 diferentes indústrias entre as firmas. O setor de energia elétrica, por sua vez, está sujeito ao imperativo regulatório da Lei $n^{\circ}$ 9.991/2000 (BRASIL, 2000). A referida norma estabelece que, até 2022, no mínimo $0,5 \%$ da receita líquida deve ser destinado a $P \& D$ e a programas de eficiência energética (Brasil, 2000). Os outros setores presentes na amostra são o de tecnologia da informação ( $8 \%$ das empresas), o segmento financeiro (4\%), além de distribuição de químicos e petroquímicos, serviços educacionais e construção civil (juntos, representam 6\% da amostra). Entre os subsetores com maior participação relativa dos gastos com $P \& D$ na receita líquida figuram a indústria de equipamentos hospitalares $(5,1 \%)$, a tecnologia da informação $(5 \%)$ e os serviços educacionais $(4,5 \%)$.

Lo (2010) explica que a materialidade é apenas um aspecto da relevância informacional e que determinados itens contábeis podem ser materiais para certo grupo de stakeholders, e imateriais para outro. Apesar dos percentuais aparentemente não representativos, as empresas podem entender que esse disclosure é de interesse para o investidor. Por outro lado, o CPC 04 (R1) não faz menção à omissão da evidenciação dos gastos com $\mathrm{P} \& \mathrm{D}$ pela não materialidade do gasto, mas há no CPC 00 (R1) uma discussão nesse sentido.

\subsection{Value relevance dos gastos com P\&D}

Conhecido o perfil das empresas da amostra, e em vista do propósito deste estudo, a Tabela 3 evidencia os resultados da análise de value relevance dos gastos com P\&D no mercado brasileiro. 
Tabela 3 - Análise de value relevance dos gastos com P\&D - critério amplo

\begin{tabular}{|c|c|c|c|c|c|c|}
\hline \multirow{2}{*}{ Variável } & $\begin{array}{r}\text { Modelo } 1 \\
\text { Pa }\end{array}$ & $\begin{array}{c}\text { Modelo } 2 \\
\text { inéis desbala }\end{array}$ & $\begin{array}{l}\text { Modelo } 3 \\
\text { anceados }\end{array}$ & Modelo 4 & $\begin{array}{l}\text { Modelo } 5 \\
\text { Painéis balan }\end{array}$ & $\begin{array}{l}\text { Modelo } 6 \\
\text { ceados }\end{array}$ \\
\hline & \multicolumn{6}{|c|}{ Coeficientes ${ }^{(\mathrm{a}, \mathrm{b})}$} \\
\hline Constante & 7880 & 0,7956 & $\mathbf{0 , 7 8 5 9}$ & 0,7965 & 993 & 0,7929 \\
\hline $\mathrm{t}$ valor & $29,57^{(* * *)}$ & $28,27^{(* * *)}$ & $28,38^{(* * *)}$ & $26,85^{(* * *)}$ & $25,66^{(* * *)}$ & $25,62^{(* * *)}$ \\
\hline$P l_{i, t}$ & $\begin{array}{r}\mathbf{0 , 1 6 0 5} \\
53^{(* * *)}\end{array}$ & $\begin{array}{r}\mathbf{0 , 1 6 0 9} \\
544^{(* * *)}\end{array}$ & $\begin{array}{r}\mathbf{0 , 1 6 0 5} \\
5,43^{(* * *)}\end{array}$ & $\begin{array}{r}\mathbf{0 , 1 5 2 6} \\
462^{(* * *)}\end{array}$ & $\begin{array}{r}\mathbf{0 , 1 5 2 7} \\
462^{(* * *)}\end{array}$ & $\begin{array}{r}\mathbf{0 , 1 5 2 5} \\
4.62(* * *)\end{array}$ \\
\hline$L L_{i, t}$ & 0,4650 & 0,4679 & 0,4640 & 0,5441 & 0,5456 & 0,5418 \\
\hline $\mathrm{t}$ valor & $5,63^{(* * *)}$ & $5,63^{(* * *)}$ & $5,60^{(* * *)}$ & $5,57^{(* * *)}$ & $5,54(* * *)$ & $5,52(* * *)$ \\
\hline$O I_{i, t}$ & - & $-0,0472$ & 4,1449 & - & $-0,0177$ & 8,7500 \\
\hline t valor & - & $-0,89$ & 0,32 & - & $-0,32$ & 0,49 \\
\hline $\mathrm{N}^{\circ}$ de observações & 1.241 & 1.241 & 1.241 & 1.005 & 1.005 & 1.005 \\
\hline $\mathrm{R}^{2}$ ajustado & 0,0804 & 0,0808 & 0,0805 & 0,0819 & 0,0820 & 0,0821 \\
\hline Estatística F & $36,19^{(* * *)}$ & $23,94(* * *)$ & $24,28^{(* * *)}$ & $30,35^{(* * *)}$ & $20,21^{(* * *)}$ & $20,49^{(* * *)}$ \\
\hline
\end{tabular}

Fonte: elaboração própria.

Legenda: Os Modelos 1 e 4 compreendem a estimação original de Ohlson (1995) sem a inclusão da variável "outras informações"; os Modelos 2 e 5 incluem a variável de interesse $O I_{i, t}$, referindo-se à divulgação de gastos com P\&D em Notas Explicativas (variável dicotômica); os Modelos 3 e 6 incluem a variável de interesse $O I_{i, t}$, referindo-se à proporção dos gastos com $\mathrm{P} \& \mathrm{D}$ em relação à receita líquida; ${ }^{\mathrm{a}}$ erros-padrão robustos estimados com correção de heteroscedasticidade de White; ${ }^{b}$ estimações de dados em painel com efeitos fixos; $(*)$ significativo a $10 \%,(* *)$ significativo a $5 \%$ e $(* * *)$ significativo a $1 \%$.

Os resultados da Tabela 3 foram obtidos pelo critério amplo, e todas as empresas compõem a avaliação, sendo os modelos 1, 2 e 3 painéis desbalanceados, enquanto os modelos 4, 5 e 6 constituem painéis balanceados. Os modelos 1 e 4 constituem a estimação original do modelo de Ohlson (1995) desconsiderando-se a variável de interesse "outras informações". Observa-se que as variáveis contábeis $P l_{i, t}$ e $L L_{i, t}$ apresentam significância estatística, evidenciando o seu papel informativo para o mercado. O impacto das variáveis no valor das firmas é positivo, indicando que os agregados contábeis contribuem para a precificação dos títulos acionários. Em ambos a significância estatística é de $1 \%$ e o poder explicativo dos modelos é pouco superior a $8 \%$. Já os modelos 2 e 5 incluem na estimação a variável representativa de "outras informações" $O I_{i, t}$, sendo ela dicotômica para captar o possível efeito do disclosure dos dispêndios com P\&D no valor das firmas. Constata-se nesses modelos que a divulgação dos gastos com P\&D não é um fator de distinção das firmas, não havendo impacto da informação no valor das firmas. Essa inferência é corroborada pelo fato de a variável $O I_{i, t}$ não dispor de significância estatística e o incremento do poder explicativo nos modelos ser inexpressivo com a adição do disclosure de P\&D. Esses resultados levam à rejeição da hipótese H1, sugerindo evidências de que o mercado brasileiro não reage à divulgação dos gastos com atividades de inovação via $P \& D$.

Os modelos 3 e 6 consideram o montante gasto com $P \& D$, sendo a variável $O I_{i, t}$ relatada como a relação $P e D_{i, t} / \operatorname{Rec}_{i, t}$, ou seja, esperava-se que maiores dispêndios com $\mathrm{P} \& \mathrm{D}$ poderiam 
Andrezza de Albuquerque Espíndola, José Glauber Cavalcante dos Santos, Alessandra Carvalho de Vasconcelos

ter impacto no valor das firmas. Contudo, as estimações demonstram que, da mesma forma que o disclosure, o montante gasto com atividades inovadoras não constitui fator distintivo na precificação dos títulos acionários no mercado brasileiro. A variável de interesse, mais uma vez, não apresentou significância estatística, e o poder explicativo visto nos modelos tem baixo incremento. Dessa forma, não há ganho informacional com o disclosure dos valores gastos com $\mathrm{P} \& \mathrm{D}$, sendo a informação, para o contexto investigado, desprovida de value relevance. Essas evidências também levam à rejeição da hipótese $\mathbf{H}_{2}$. Azevedo e Gutierrez (2009) divergem em relação às conclusões desta pesquisa, porém examinam empresas americanas listadas na Nyse, pertencentes a um mercado comparativamente maior, mais desenvolvido e consolidado economicamente. Por seu turno, Alves et al. (2011) apontam para conclusão similar, analisando-se apenas as empresas do setor de energia elétrica entre 2002 e 2009. Rodrigues, Elias e Campos (2015) concluíram que a informação sobre P\&D dispunha de value relevance apenas no período subsequente ao padrão contábil internacional, obrigatório para o Brasil desde 2010, investigando 326 empresas entre 2003 e 2012. Em outros contextos econômicos desenvolvidos, os resultados da pesquisa corroboram os achados de Atoche, López e Ruiz (2012), parcialmente, os de Gong e Wang (2016), e contrariam os achados de Franzen e Radhakrishnan (2009) e Oswald (2008).

A Tabela 4 apresenta os resultados da análise de regressão por meio do critério restrito (apenas as firmas que divulgaram as informações de P\&D).

Tabela 4 - Análise de value relevance dos gastos com P\&D - critério restrito

\begin{tabular}{|c|c|c|c|c|}
\hline \multirow{3}{*}{ Variável } & Modelo 7 & Modelo 8 & Modelo 9 & Modelo 10 \\
\hline & Painéis desb & alanceados & \multicolumn{2}{|c|}{ Painéis balanceados } \\
\hline & \multicolumn{4}{|c|}{ Coeficientes $^{(a, b)}$} \\
\hline Constante & 0,7199 & 0,6943 & 0,7886 & $\mathbf{0 , 8 1 2 9}$ \\
\hline t valor & $17,25^{(* * *)}$ & $8,71^{(* * *)}$ & $18,57^{(* * *)}$ & $9,08^{(* * *)}$ \\
\hline$P l_{i, t}$ & 0,1905 & 0,1921 & 0,1184 & 0,1175 \\
\hline $\mathrm{t}$ valor & $4,74^{(* * *)}$ & $4,70^{(* * *)}$ & $3,35^{(* * *)}$ & $3,36^{(* * *)}$ \\
\hline$L L_{i, t}$ & 0,3098 & 0,3164 & 0,2248 & 0,2197 \\
\hline t valor & $1,91^{(*)}$ & $1,89^{(*)}$ & 1,47 & 1,35 \\
\hline$O I_{i, t}$ & - & 2,7855 & - & $-2,8477$ \\
\hline $\mathrm{t}$ valor & - & 0,39 & - & $-0,30$ \\
\hline $\mathrm{N}^{\circ}$ de observações & 208 & 208 & 145 & 145 \\
\hline $\mathrm{R}^{2}$ ajustado & 0,0872 & 0,0879 & 0,0492 & 0,0497 \\
\hline Estatística F & $13,80^{(* * *)}$ & $9,07^{(* * *)}$ & $6,60^{(* * *)}$ & $4,58^{(* * *)}$ \\
\hline
\end{tabular}

Fonte: elaboração própria.

Legenda: Os modelos7 e 9 compreendem a estimação original de Ohlson (1995) sem a inclusão da variável "outras informações"; os modelos 8 e 10 incluem a variável de interesse $O I_{i, t}$, referindo-se à proporção dos gastos com P\&D em relação à receita líquida; erros-padrão robustos estimados com correção de heteroscedasticidade de White; estimações de dados em painel com efeitos fixos; (*) significativo a $10 \%,(* *)$ significativo a $5 \%$ e $(* * *)$ significativo a $1 \%$. 
A análise de relevância informacional com critério restrito, em que foram consideradas na avaliação apenas as firmas com $\mathrm{P} \& \mathrm{D}$, ratifica as conclusões anteriores. Portanto, a proporção dos gastos com P\&D em relação à receita líquida das empresas não agrega conteúdo informacional para o mercado de capitais brasileiro. Nessa análise, a variável contábil $L L_{i, t}$ é estatisticamente significante apenas ao nível de 10\% (painéis desbalanceados). Avaliando-se painéis balanceados, o poder explicativo dos modelos é inferior a 5\%, e o $L L_{i, t}$ dessas empresas não explica o valor atribuído pelo mercado, identificando-se, assim, uma anomalia no modelo de Ohlson (1995) para análise de value relevance de itens contábeis e não contábeis.

\subsection{Discussão}

Os resultados apresentados e confrontados com a literatura corroboram os achados de Beisland e Hamberg (2013), segundo os quais a value relevance reflete o contexto econômico investigado. Talvez o contexto econômico brasileiro não estimule suficientemente a articulação de esforços direcionados para atividades de inovação nas empresas. Basta verificar que apenas $15 \%$ das 440 firmas examinadas faziam divulgação dos gastos com P\&D. Lembra-se que dentro dessa parcela há empresas do setor energético, condicionadas a investir em inovação via $\mathrm{P} \& \mathrm{D}$ por meio de imperativo regulatório/normativo. Com isso, o investidor passa a não atribuir relevância a esse tipo de informação.

Siekkinen (2015) afirma que em um ambiente de baixa proteção acionária as firmas tendem a não apresentar value relevance. Outra questão que poderia explicar o panorama apresentado é a incerteza associada aos benefícios econômicos derivados da atividade de inovação. Azevedo e Gutierrez (2009) e Santos et al. (2016) entendem que os impactos do P\&D poderiam vir a ser sentidos na firma apenas em horizontes de longo prazo. Assim, o risco e a baixa rentabilidade do esforço financeiro poderiam contribuir para o desestímulo do investidor e das empresas, justificando-se a ausência de value relevance da variável.

Minetti, Murro e Paiella (2015) observaram que o alto nível de concentração acionária afeta negativamente a inovação, o que pode justificar o baixo investimento em P\&D no Brasil, já que a concentração de propriedade no país é alta. Ressalta-se que a alta concentração acionária é uma resposta ao ambiente de fraco enforcement, e que essa também pode ser uma explicação para o aparente desinteresse do mercado em relação aos gastos com P\&D (GONG; WANG, 2016; TERRA; LIMA, 2006). Ao menos, no caso do Brasil, os dispêndios com P\&D não sinalizam para o mercado projetos arriscados e pouco interessantes no que tange ao retorno 
Andrezza de Albuquerque Espíndola, José Glauber Cavalcante dos Santos, Alessandra Carvalho de Vasconcelos

econômico; mas também não sinalizam vantagens competitivas futuras, como explicam Atoche, López e Ruiz (2012).

Questiona-se a obrigatoriedade da divulgação desses accruals diante da "neutralidade" do investidor, pois esta pesquisa abrangeu período de consolidação das IFRS no Brasil, que trouxe esse imperativo efetivamente a partir de 2010. Segundo Gong e Wang (2016) e Rodrigues, Elias e Campos (2015), a relevância informacional dos gastos com P\&D inexiste ou é reduzida com as IFRS, que deram tratamento contábil de baixa capitalização desses gastos. Talvez se a natureza das atividades de $\mathrm{P} \& \mathrm{D}$ fosse relatada nas Notas Explicativas o efeito desses gastos poderia ser mais bem captado pelos investidores, resguardado o sigilo industrial. O CPC 04 (R1) obriga apenas a divulgação dos gastos, sem exigir o detalhamento dos projetos. Por outro lado, os gastos com P\&D lançados no resultado caracterizam pesquisa básica, sem benefícios econômicos a eles diretamente associados, justificando os resultados observados para o contexto brasileiro.

Adiciona-se ainda o fato de que o imperativo regulatório via Lei $\mathrm{n}^{\text {o }}$ 9.991/2000 (BRASIL, 2000) pode fazer com que o mercado não atribua relevância informacional aos gastos com $\mathrm{P} \& \mathrm{D}$, pois nesse caso as despesas possuem efeito fiscal, não gerando benefícios direitos às empresas de energia elétrica. Por exemplo, uma parte dos recursos recolhido é utilizado para financiar o Fundo Nacional de Desenvolvimento Científico e Tecnológico (FNDCT), outra parcela para projetos estabelecidos pela Agência Nacional de Energia Elétrica (ANEEL). Esses projetos, embora possam beneficiar as empresas de energia no futuro, não estão alinhados com a ideia de inovação como diferencial de competitividade e diferenciação devido à regulação setorial.

\section{CONSIDERAÇÕES FINAIS}

Esta pesquisa teve como objetivo analisar a relevância da divulgação dos gastos com P\&D para o mercado de capitais brasileiro no período de 2011 a 2015.

A análise preliminar revelou empresas pouco comprometidas em financiar projetos direcionados para a inovação via P\&D, fato também apontado por Teh, Kayo e Kimura (2008). Evidencia-se, no contexto brasileiro, um cenário de fraco compromisso com estratégias dessa natureza. Em linhas gerais, os resultados indicam que os recursos aplicados em atividades de P\&D sofreram oscilação no período. Sugere-se que a realização desses dispêndios não é representativa. Na pesquisa, houve a preocupação de abordar os efeitos desses dispêndios com 
P\&D na expectativa do investidor. Logo, a questão que poderia complementar as óticas de análise anteriores tem a ver com a possível contribuição de longo prazo do gasto com $\mathrm{P} \& \mathrm{D}$ para a empresa. Em outras palavras, os ganhos não seriam imediatos, daí poderem talvez ser incorporados ao valor das empresas, não no desempenho corrente ou de curto prazo. A análise setorial econômica apontou a presença latente do setor industrial e de energia elétrica, sendo estes considerados, em tese, os mais inovadores, seja pela atividade em si ou por imperativos regulatórios, como no caso do setor elétrico.

Feita a análise de relevância, concluiu-se que a hipótese $\mathbf{H}_{1}$ seria rejeitada, já que a divulgação de gastos com P\&D não gera impacto na informação do valor das firmas. Em seguida, inferiu-se, por meio de modelos que consideravam a variável de interesse $\mathrm{P} \& \mathrm{D}$, que não constitui fator distintivo na precificação das ações das empresas o montante investido em atividades de inovação. Em suma, feitas as análises de regressão, observou-se que o valor investido em P\&D não é capaz de incrementar o valor de mercado das empresas, rejeitando-se também a hipótese $\mathbf{H}_{2}$. Ou seja, conclui-se que, no mercado de capitais brasileiro, dados a amostra e os períodos analisados neste estudo, os dispêndios realizados em inovação, com foco em P\&D, não influenciam o valor de mercado das empresas. Devido à baixa representatividade do valor gasto com $P \& D$, quando comparado com o da receita líquida, conjectura-se que essa seja uma justificativa para a não significância da informação quanto à precificação dos títulos acionários. Outra conjectura seria o desestímulo do ambiente econômico brasileiro, que, por questões de custo ou incerteza, torna desinteressante investir em atividades inovadoras.

Espera-se que os resultados desta pesquisa venham a contribuir para enriquecer a literatura acerca de relevância informacional dos gastos com $\mathrm{P} \& \mathrm{D}$, dada a pequena quantidade de estudos da temática abordando o mercado de capitais brasileiro como um todo. É válido ressaltar a obrigatoriedade de divulgar os gastos com P\&D, porém, diante dos resultados obtidos, eles não se mostram relevantes, fazendo suscitar, então, um aspecto que poderá ser discutido em estudos futuros: sendo a informação não relevante para o mercado, é interessante questionar até que ponto esse disclosure beneficia as firmas e os stakeholders. A pesquisa tem algumas limitações, haja vista a escassez de informações relacionadas às atividades de P\&D divulgadas pelas firmas no Brasil, assim como o pequeno tamanho da amostra e o período selecionado, não permitindo uma análise mais profunda e vasta de cada setor comparativamente. A fim de incrementar o campo de estudo, novas análises poderão vir a comparar a realidade de outros países com a brasileira, tendo em vista as suas diferenças até mesmo no tocante ao disclosure contábil. 


\section{REFERENCIAS}

AHARONY, Joseph; BARNIV, Ran; FALK, Haim. The impact of mandatory IFRS adoption on equity valuation of accounting numbers for security investors in the EU. European Accounting Review, v. 19, n. 03, p. 535-578, 2010.

AHMED, Kamran; FALK, Haim. The value relevance of management's research and development reporting choice: evidence from Australia. Journal of Accounting and Public Policy, v. 25, n. 03, p. 231-264, 2006.

AKERLOF, George A. The market for "lemons": quality uncertainty and the market mechanism. The Quarterly Journal of Economics, v. 84, n. 03, p. 488-500, 1970.

ALVES, Alessandro Pereira; SILVA, Tatiane Gomes; MACEDO, Marcelo Álvaro da Silva; MARQUES, José Augusto Veiga da Costa. A relevância dos gastos com P\&D para o mercado Brasileiro de capitais: um estudo com distribuidoras de energia elétrica no período de 2002 a 2009. Revista de Administração e Inovação, v. 08, n. 02, p. 216-239, 2011.

ANDREASSI, Tales; SBRAGIA, Roberto. Relações entre indicadores de P\&D e de resultado empresarial. Revista de Administração da Universidade de São Paulo, v. 37, n. 01, 2002.

ATOCHE, Teresa Duarte; LÓPEZ, José Ángel Pérez; RUIZ, Jose Antonio Camúñez. La relevancia de los gastos de I+D: estudio empírico en el sector del automóvil. Revista de Contabilidad, v. 15, n. 02, p. 257-286, 2012.

AZEVEDO, Fabrício Nunes; GUTIERREZ, Carlos Enrique Carrasco. A relação dos gastos com P\&D na taxa de crescimento de longo prazo das empresas listadas na NYSE. In: CONGRESSO IAAER-ANPCONT. Anais... São Paulo, 3, 2009.

BAAIJ, Marc; GREEVEN, Mark; VAN DALEN, Jan. Persistent superior economic performance, sustainable competitive advantage, and Schumpeterian innovation: leading established computer firms, 1954-2000. European Management Journal, v. 22, n. 05, p. 517 531, 2004.

BALL, Ray; BROWN, Philip. An empirical evaluation of accounting income numbers. Journal of Accounting Research, Autumn, p. 159-178, 1968.

BARNEY, Jay. Firm resources and sustained competitive advantage. Journal of Management, v. 17, n. 01, p. 99-120, 1991. 
BEAVER, William. H. The information content of annual earnings announcements. Journal of Accounting Research, v. 06, p. 67-92, 1968.

BEISLAND, Leif Atle; HAMBERG, Mattias. Earnings sustainability, economic conditions and the value relevance of accounting information. Scandinavian Journal of Management, 29, p. 314-324, 2013.

BRASIL. Lei no 9.991, de 24 de julho de 2000. Dispõe sobre realização de investimentos em pesquisa e desenvolvimento e em eficiência energética por parte das empresas concessionárias, permissionárias e autorizadas do setor de energia elétrica, e dá outras providências. Disponível em: <http://www.planalto.gov.br/ccivil_03/leis/L9991.htm>. Acesso em: 11 mar. 2017.

BRITO, Eliane Pereira Zamith; BRITO, Luiz Artur Ledur; MORGANTI, Fábio. Inovação e o desempenho empresarial: lucro ou crescimento? Revista de Administração de Empresas, v. 08, n. 01, Art. 6, 2009.

BROWN, Stephen; LO, Kin; LYS, Thomas. Use of $\mathrm{R}^{2}$ in accounting research: measuring changes in value relevance over the last four decades. Journal of Accounting and Economics, v. 28, p. $83-115,1999$.

CARAYANNIS, Elias. G.; SAMARA, Elpida. T.; BAKOUROS, Yannis. L. Innovation and entrepreneurship: theory, policy and practice. Switzerland: Springer, 2015.

CARMONA, Linda Jessica de Montreuil; TOMELIN, Jurema; DANI, Andreia Carpes; HEIN, Nelson. Efeito da intensidade tecnológica na relação entre o investimento em inovação e o desempenho organizacional de setores industriais. Revista Brasileira de Gestão e Inovação, v. 05, n. 02, p. 84-106, 2018.

CARVALHO, Francisval de Melo; KAYO, Eduardo Kazuo; MARTIN, Diógenes Manoel Leiva. Tangibilidade e intangibilidade na determinação do desempenho persistente de firmas brasileiras. Revista de Administração Contemporânea, v. 14, n. 05, p. 871-889, 2010.

CHANEY, Paul K; TIMOTHY M. Devinney; RUSSELL S. Winer. The impact of new product introductions on the market value of firms. The Journal of Business, v. 64, n. 4, p. 573-610, 1991.

CHO, Hee-Jae; PUCIK, Vladimir. Relationship between innovativeness, quality, growth, profitability, and market value. Strategic Management Journal, v. 26, n. 6, p. 555-575, 2005. 
Andrezza de Albuquerque Espíndola, José Glauber Cavalcante dos Santos, Alessandra Carvalho de Vasconcelos

CPC - Comitê de Pronunciamentos Contábeis. CPC 00 (R1) - Estrutura Conceitual para Elaboração e Divulgação de Relatório Contábil-Financeiro. 2011. Disponível em: <http://www.cpc.org.br/CPC/Documentos-

Emitidos/Pronunciamentos/Pronunciamento?Id=80>. Acesso em: 10 mar. 2017.

- $\quad$ CPC 04 (R1) - Ativo Intangível. 2010. Disponível em:

<http://www.cpc.org.br/CPC/Documentos-

Emitidos/Pronunciamentos/Pronunciamento?Id=35>. Acesso em: 10 mar. 2017.

CRUZ, Adejard Gaia. Adoção e difusão de inovação no estado do Pará: uma análise a partir do sistema regional de inovação (1995-2006). Dissertação (Mestrado em Desenvolvimento Sustentável do Trópico Úmido) - Universidade Federal do Pará, Belém, PA, Brasil, 2007.

DYE, Ronald. A. Disclosure of nonproprietary information. Journal of Accounting Research, v. 23, n. 01, p. 123-145, 1985.

FRANCIS, Jennifer; SCHIPPER, Katherine. Have financial statement lost their relevance? Journal of Accounting Research, v. 37, n. 02, p. 319-352, 1999.

FRANZEN, Laurel; RADHAKRISHNAN, Suresh. The value relevance of R\&D across profit and loss firms. Journal of Account and Public Policy, v. 28, n. 01, p. 16-31, 2009.

GONG, James Jianxin; WANG, Sophia I-Ling. Changes in the value relevance of research and development expenses after IFRS adoption. Advances in Accounting, Incorporating Advances in International Accounting, v. 35, p. 49-61, 2016.

GU, Feng; LI, John Q. Disclosure of innovation activities by high-technology firms. AsiaPacific Journal of Accounting \& Economics, v. 10, n. 02, p. 143-172, 2003.

HAMBERG, Mattias; BEISLAND, Leif-Atle. Changes in the value relevance of goodwill accounting following the adoption of IFRS 3. Journal of International Accounting, Auditing and Taxation, v. 23, p. 59-73, 2014.

HOLTHAUSEN, Robert W; WATTS, Ross L. The relevance of the value-relevance literature for financial accounting standard setting. Journal of Accounting \& Economics, 31, 3-75, 2001.

IAS PLUS. IAS (International Accounting Standard) 38 - Intangible assets. s.d. Disponível em: <https://www.iasplus.com/en/standards/ias/ias38\#link20>. Acesso em: 10 mar. 2017. 
IFRS - International Financial Reporting Standards Foundation. Conceptual Framework. s.d. Disponível em: <http://www.ifrs.org/projects/work-plan/conceptual-framework/\#about>. Acesso em: 10 mar. 2017.

JENSEN, Juan; MENEZES-FILHO, Naércio; SBRAGIA, Roberto. Os determinantes dos gastos em P\&D no Brasil: uma análise com dados em painel. Estudos Econômicos, v. 34, n. 04, p. 661-691, 2004.

JIANG, Wei; STARK, Andrew W. Dividends, research and development expenditures, and the value relevance of book value for UK loss-making firms. The British Accounting Review, v. 45, n. 02, p. 112-124, 2013.

LEE, Jooh; SHIM, Eunsup. Moderating effects of R\&D on corporate growth in U. S. and Japanese hi-tech industries: An empirical study. The Journal of High Technology Management Research, v. 06, n. 02, p. 179-191, 1995.

LO, Kin. Materiality and voluntary disclosures. Journal of Accounting and Economics, v. 49, n. 1-2, p. 133-135, 2010.

LOPES, Alexsandro Broedel; SANT’ANNA, Dimitri; COSTA, Fábio Moraes. A relevância das informações contábeis na Bovespa a partir do arcabouço teórico de Ohlson: avaliação dos modelos de Residual Income Valuation e Abnormal Earnings Growth. Revista de Administração. São Paulo, v. 42, n. 04, p. 497-510, 2007.

LUNDHOLM, Russell; MYERS, Linda A. Bringing the future forward: the effect of disclosure on the returns-earnings relation. Journal of Accounting Research, v. 40, n. 03, 2002.

MACHADO, Márcio André Veras; MACEDO, Marcelo Alvaro da Silva; MACHADO, Márcia Reis. Análise da relevância do conteúdo informacional da DVA no mercado brasileiro de capitais. Revista de Contabilidade e Finanças, São Paulo, v. 26, n. 67, p. 57-69, 2015.

MADEIRA, Fábio Lopes; COSTA JUNIOR, Jorge Vieira. Value relevance dos outros resultados abrangentes nas companhias abertas brasileiras. Advances in Scientific and Applied Accounting, São Paulo, v. 08, n. 02, p. 204-217, 2015.

MARCH, James G. Exploration and exploitation in organizational learning. Organization Science, v. 2, n. 01, p. 71-87, 1991.

MILLER, Gregory S. Earnings performance and discretionary disclosure. Journal of Accounting Research, v. 40, n. 01, p. 173-204, 2002. 
Andrezza de Albuquerque Espíndola, José Glauber Cavalcante dos Santos, Alessandra Carvalho de Vasconcelos

MINETTI, Raoul; MURRO, Pierluigi; PAIELLA, Monica. Ownership structure, governance, and innovation. European Economic Review, v. 80, p. 165-193, 2015.

MYERS, Stewart C.; MAJLUF, Nicholas S. Corporate financing and investment decisions when firms have information that investors do not have. Journal of Financial Economics, v. 13, p. 187-221, 1984.

NGUYEN, Pascal; NIVOIX, Sophie; NOMA, Mikiharu. The valuation of R\&D expenditures in Japan. Accounting \& Finance, v. 50, n. 04, p. 899-920, 2010.

OHLSON, James A. Earnings, book values, and dividends in equity valuation. Contemporary Accounting Research, v. 11, n. 02, p. 661-687, 1995.

OLIVEIRA, Michel Angelo Constantino; MENDES, Dany Rafael Fonseca; MOREIRA, Tito Belchior Silva; CUNHA, George Henrique de Moura. Análise econométrica dos dispêndios em pesquisa \& desenvolvimento (P\&D) no Brasil. Revista de Administração e Inovação, São Paulo, v. 12, n. 03, p. 268-286, 2015.

OSWALD, Dennis R. The determinants and value relevance of the choice of accounting for research and development expenditures in the United Kingdom. Journal of Business Finance \& Accounting, v. 35, n. 1/2, p. 1-24, 2008.

POTIN, Silas Adolfo; BORTOLON, Patrícia Maria; SARLO NETO, Alfredo. Hedge accounting no mercado acionário brasileiro: efeitos na qualidade da informação contábil, disclosure e assimetria de informação. Revista de Contabilidade e Finanças, São Paulo, v. 27, n. 71, p. 202-216, 2016.

RODRIGUES, Jomar Miranda; ELIAS, Wanderson Gonçalves; CAMPOS, Edmilson Soares. Relevância da informação contábil: uma análise dos efeitos da contabilização dos gastos com pesquisa e desenvolvimento com a aplicação da Lei 11.638/07 no mercado brasileiro. Revista de Contabilidade e Controladoria, Curitiba, v. 07, n. 03, p. 131-148, 2015.

ROMNEY, Marshall B.; STEINBART, Paul J. Accounting information systems. 8. ed. New Jersey: Prentice Hall, 2000.

SANTOS, David Ferreira Lopes; BASSO, Leonardo Fernando Cruz; KIMURA, Herbert; KAYO, Eduardo Kayo. Innovation efforts and performances of Brazilian firms. Journal of Business Research, v. 67, n. 04, p. 527-535, 2014. 
SANTOS, José Glauber Cavalcante dos; GÓIS, Alan Diógenes; REBOUÇAS, Silvia Maria Dias Pedro; SILVA FILHO, José Carlos Lázaro. Efeitos da inovação no desempenho de firmas brasileiras: rentabilidade, lucro, geração de valor ou percepção do mercado? Revista de Administração da UNIMEP, v. 14, n. 02, 2016.

SANTOS, José Glauber Cavalcante dos; VASCONCELOS, Alessandra Carvalho; DE LUCA, Márcia Martins Mendes. Perfil da inovação e da internacionalização de empresas transnacionais. Revista de Administração e Inovação, São Paulo, v. 10, n. 01, p. 198-211, 2013.

SIEKKINEN, Jimi. Value relevance of fair values in different investor protection environments. Accounting Forum, v. 40, p. 1-15, 2016.

SILVA, José Carlos Lázaro; BRAGA, Clara Suzana Cardoso; REBOUÇAS, Silvia Maria Dias Pedro. Perception of the Brazilian manufacturing industry about the main barriers to innovation. International Journal of Innovation (IJI Journal), v. 05, n 01, p. 114-131, 2017.

SIMON, Herbert A. A behavioral model of rational choice. The Quarterly Journal of Economics, v. 69, n. 01, p. 99-118, 1955.

SONGUR, Hilmi; HEAVILIN, Jason E. Abnormal research and development investments and stock returns. North American Journal of Economics and Finance, v. 42, p. 237-249, 2017.

SOUZA, Maíra Melo de; BORBA, José Alonso. Value relevance do nível de disclosure das combinações de negócios e do goodwill reconhecido nas companhias de capital aberto brasileiras. Revista de Contabilidade e Finanças, São Paulo, v. 28, n. 73, p. 77-92, 2017.

SPENCE, Michael. Job market signaling. The Quarterly Journal of Economics, v. 87, n. 03, p. 355-374, 1973.

TEH, Chang Chuan; KAYO, Eduardo Kazuo; KIMURA, Herbert. Marcas, patentes e criação de valor. Revista de Administração Mackenzie, v. 09, n. 01, p. 86-106, 2008.

TERRA, Paulo Renato Soares; LIMA, João Batista Nast de. Governança corporativa e a reação do mercado de capitais à divulgação das informações contábeis. Revista Contabilidade \& Finanças, v. 17, n. 42, p. 35-49, 2006.

ZEMPLINEROVÁ, Alena; HROMÁDKOVÁ, Eva. Determinants of firm's innovation. Prague Economic Papers, v. 21, n. 04, p. 487-503, 2012. 